\title{
Understanding Kelvin-Helmholtz instability in paraffin-based hybrid rocket fuels
}

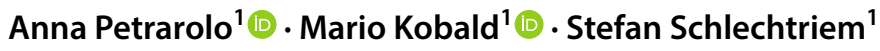

Received: 7 December 2017 / Revised: 15 February 2018 / Accepted: 20 February 2018 / Published online: 5 March 2018

(C) The Author(s) 2018. This article is an open access publication

\begin{abstract}
Liquefying fuels show higher regression rates than the classical polymeric ones. They are able to form, along their burning surface, a low viscosity and surface tension liquid layer, which can become unstable (Kelvin-Helmholtz instability) due to the high velocity gas flow in the fuel port. This causes entrainment of liquid droplets from the fuel surface into the oxidizer gas flow. To better understand the droplets entrainment mechanism, optical investigations on the combustion behaviour of paraffin-based hybrid rocket fuels in combination with gaseous oxygen have been conducted in the framework of this research. Combustion tests were performed in a 2D single-slab burner at atmospheric conditions. High speed videos were recorded and analysed with two decomposition techniques. Proper orthogonal decomposition (POD) and independent component analysis (ICA) were applied to the scalar field of the flame luminosity. The most excited frequencies and wavelengths of the wave-like structures characterizing the liquid melt layer were computed. The fuel slab viscosity and the oxidizer mass flow were varied to study their influence on the liquid layer instability process. The combustion is dominated by periodic, wavelike structures for all the analysed fuels. Frequencies and wavelengths characterizing the liquid melt layer depend on the fuel viscosity and oxidizer mass flow. Moreover, for very low mass flows, no wavelength peaks are detected for the higher viscosity fuels. This is important to better understand and predict the onset and development of the entrainment process, which is connected to the amplification of the longitudinal waves.
\end{abstract}

\section{List of symbols}

$A_{\text {cross }} \quad$ Area crossed by the oxidizer mass flow $\left(\mathrm{m}^{2}\right)$

$B \quad$ Constant for the perturbation expression (-)

$G_{\text {Ox }} \quad$ Oxidizer mass flux $\left(\mathrm{kg} / \mathrm{m}^{2} \mathrm{~s}\right)$

$K_{0,1,2}$ Dispersion relation constants (-)

$U \quad$ Gas velocity $(\mathrm{m} / \mathrm{s})$

$a, n \quad$ Regression rate parameters (-)

$g \quad$ Gravity acceleration $\left(\mathrm{m} / \mathrm{s}^{2}\right)$

$h \quad$ Height (m)

$k \quad$ Wave number $(1 / \mathrm{m})$

$\dot{m}_{\text {Ox }} \quad$ Oxidizer mass flow $(\mathrm{kg} / \mathrm{s})$

$r_{\mathrm{f}} \quad$ Regression rate $(\mathrm{m} / \mathrm{s})$

$t \quad$ Time (s)

$x \quad$ Longitudinal coordinate $(\mathrm{m})$

$\gamma \quad$ Surface tension $(\mathrm{N} / \mathrm{m})$

$\mu \quad$ Kinematic viscosity (Pa s)

$\rho \quad$ Density $\left(\mathrm{kg} / \mathrm{m}^{3}\right)$

$\omega \quad$ Wave frequency $(1 / \mathrm{s})$

Anna Petrarolo

anna.petrarolo@dlr.de

1 German Aerospace Center (DLR), Institute of Space Propulsion, 74239 Hardthausen, Germany

\author{
Subscripts \\ G Gas \\ I Imaginary part \\ $L \quad$ Liquid \\ $R \quad$ Real part
}

\section{Introduction}

\subsection{Hybrid rocket propulsion}

Hybrid rocket engines (HRE) are generally made up of a solid fuel and a liquid or gaseous oxidizer. The combustion develops within the turbulent boundary layer over the fuel surface and the flame is located where the vaporized oxidizer and fuel exist in a combustible mixture (Marxman and Gilbert 1963). The heat is then radiated and convected from the flame to the fuel surface, in a self-sustained but diffusion-limited process. In a classical hybrid, the polymeric fuel pyrolyses and its vapours are transported to the diffusion flame, where it reacts with the atomized oxidizer transported from the free stream via turbulent diffusion (Chiaverini 2007). The diffusion-limited combustion process that characterizes conventional polymeric hybrid fuels, such as 
hydroxyl-terminated polybutadiene (HTPB) or high-density polyethylene (HDPE), leads to a low regression rate and, consequently, to low thrust levels with respect to solid or liquid rocket engines. To overcome this problem, the available burning area has typically been increased through the use of multi-port fuel grains. Unfortunately, this leads to complex grain geometries, low volumetric loading, increase of the residual mass of unburned fuel (which leads to a decrease in the delivered specific impulse) and uneven burning. Because of this, the use of hybrid propulsion systems has been hindered in the past despite their advantages with respect to solid and liquid engines. In fact, due to the fact that the propellants are stored in two different states of matter, hybrids are safer than solid motors. This also contributes to reduce the total costs of the engine. Moreover, they are characterized by controllable thrust, including shut off and restart capability. With respect to liquid engines, they are mechanically simpler and, consequently, cheaper. Finally, they have increased performance compared to solids and generally a specific impulse nearly comparable to liquid systems (Chandler 2012).

Recently, a new class of high regression rate hybrid rocket fuels has been discovered at Stanford University. This has enabled the use of simple, single port fuel grain designs and has revitalized the interest in hybrid propulsion systems. These fast burning fuels are characterized by low viscosity and surface tension and they experience a different combustion mechanism with respect to conventional polymeric fuels (Karabeyoglu et al. 2001). They form a thin liquid layer on the fuel surface during the combustion (Karabeyoglu et al. 2002). It is expected that the low viscosity and surface tension of the liquid fuel enable an additional mass transfer by entrainment of liquid droplets. The gas flow over the surface induces liquid layer instabilities (Kelvin-Helmholtz instability), which produce the droplet entrainment (Karabeyoglu and Cantwell 2002), see also Fig. 1. The entrainment mechanism works like a spray injection along the length of the motor, which increases the effective fuel burning area and reduces the blocking effect.

Optical results of the entrainment process of low viscosity liquefying fuels produced within this research are shown in Fig. 2. Recent tests with different paraffin-based fuels and gaseous oxygen (GOX) showed an exponential relation between the liquid layer viscosity and the overall regression rate (Kobald et al. 2017c), which proves the predicted entrainment correlation in Fig. 1. Latest results investigate more in detail the liquid layer instability process with an automatic evaluation technique and show that its application is consistent and useful for the evaluation of the combustion data (Petrarolo and Kobald 2016). The increased regression rate was also proven at higher scale in a paraffin-based hybrid sounding rocket, developed at the University of Stuttgart and the DLR Lampoldshausen. It was successfully launched in November 2016 to $32.3 \mathrm{~km}$ altitude (Kobald et al. 2017a, b).

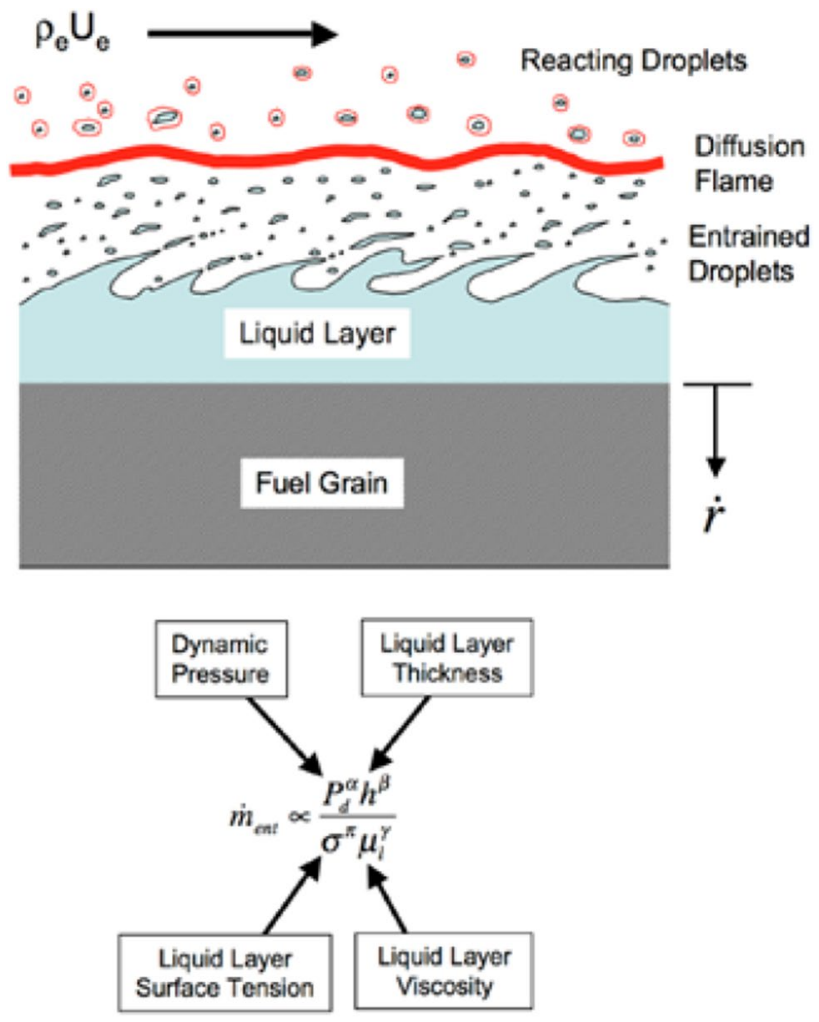

Fig. 1 Liquefying fuel combustion theory, taken from Karabeyoglu et al. (2005)

\subsection{Optical investigations on hybrid rocket combustion}

The discovery of liquefying hybrid rocket fuels has renewed the interest in hybrid propulsion and in optical investigations of the hybrid rocket combustion process. The theory of the Kelvin-Helmholtz instability (KHI) and of the liquid layer break up process, which leads to the fuel droplet entrainment, are well-explained in the literature (Karabeyoglu et al. 2002; Karabeyoglu and Cantwell 2002; Funada and Joseph 2001; Amano et al. 2016). The increase in regression rate is proven at different thrust levels by Karabeyoglu et al. (2004) and some detailed optical investigations have been performed in the recent years to capture the entrainment process. Some of them are described herein.

In 2011, Nakagawa et al. investigated the dependence of the regression rate on the fuel viscosity. They performed optical tests at atmospheric pressure with different paraffinbased fuels and gaseous oxygen. Their images showed that droplets are generated during the combustion and entrained in the flow (Nakagawa and Hikone 2011). De Luca et al. also used an optical technique to investigate the hybrid combustion process. They looked inside a pressurized chamber over a mirror set-up and thereby measured the instantaneous regression rate (DeLuca et al. 2011). 
Fig. 2 Liquefying fuel combustion image created within this research (oxidizer mass flow from left to right)

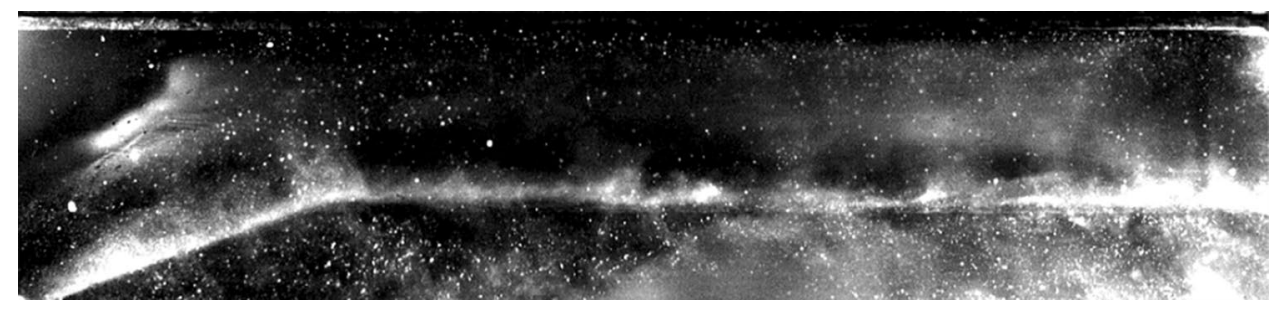

Many optical investigations on the combustion behaviour of both polymeric and paraffin-based hybrid rocket fuels have been done at the Stanford combustion visualization facility. In 2012, Chandler et al. investigated the combustion of paraffin-based fuels with gaseous oxygen at both atmospheric and elevated pressures. Their results showed roll waves and droplets in the atmospheric tests and filament-like structures along the sides of the fuel grains in the tests run at elevated pressures (Chandler et al. 2012a). Moreover, they compared the combustion behaviour of paraffin-based fuels to that of classical hybrid fuels. They reported that for paraffin-based fuels entraining droplets were visible, for high-density polyethylene (HDPE), only little droplet entrainment was seen and for hydroxyl-terminated polybutadiene (HTPB), no droplet entrainment was measured (Chandler et al. 2012b). In 2014-2016, many optical tests were conducted from Jens et al. with the same facility. They performed Schlieren and $\mathrm{OH}^{*}$ images of the combustion of different classical polymeric and paraffin-based fuels in combination with gaseous oxygen at both atmospheric and elevated pressures (Jens et al. 2016). They reported unsteady blowing events of paraffin droplets in the tests at higher pressure, slightly above the critical pressure of their paraffin samples. Schlieren results of their tests reported a thickening boundary layer with increasing pressure (Jens et al. 2014a). Tests at atmospheric pressure were conducted also with HTPB, HDPE and PMMA (polymethyl methacrylate). No drastic change in boundary layer thickness growth was observed between paraffin wax and classical polymeric fuels (Jens et al. 2014b). On the other hand, the flame zone of the paraffin wax was found to be much thicker than that of the classical fuels (Jens et al. 2015).

In 2014, Wada et al. visualized the combustion of different polymeric fuels and paraffin. The investigated pressure range was from 1 up to 20 bar. In contrast to the other mentioned optical experiments, this set-up looks at the combustion of opposing slabs of fuel mounted vertically. From their observations, they concluded that both the number and size of the entrained droplets are independent of the chamber pressure (Wada et al. 2014).

Many optical investigations have also been done at the German Aerospace Center (DLR), Institute of Space Propulsion, since 2013. Kobald et al. performed visual and
Schlieren images of the combustion of paraffin wax and gaseous oxygen at atmospheric pressure. They reported visualization of droplets entrainment during start-up and shut-down transients (Kobald and Schlechtriem 2013; Kobald et al. 2013). Since 2015, an automated video evaluation routine has been developed in DLR, to capture the dominant flow dynamic and combustion behaviour of paraffinbased hybrid rocket fuels during a typical test. The ignition, steady-state and extinction phases were clearly recognized with this technique. Moreover, the HTPB combustion flame showed no wave-like behaviour, in contrast to paraffin-based fuels (Kobald et al. 2015; Petrarolo and Kobald 2016).

The results of this research are focused on the connection between the Kelvin-Helmholtz instability mechanism and the entrainment in paraffin-based hybrid rocket engines. In particular, it is important to find the parameters that are mostly influencing the liquid layer instability process and to understand how this phenomenon is connected to the droplets entrainment rate. In this way, the fuel regression rate can be directly controlled just by triggering precise frequencies and wavelengths of the liquid layer.

In this paper, the influence of fuel properties and oxidizer mass flow on the Kelvin-Helmholtz instability mechanism is presented and discussed. It is demonstrated that there is a strict dependence between these parameters and the dynamics of the liquid layer. This is a first fundamental step in order to connect the instability process with the regression rate.

\section{Fuel choice and characterization}

\subsection{Paraffin-based fuels}

Three different paraffin-based fuels have been investigated in the framework of this research. The wax that has been used as a baseline for all the fuels is type 6805 from the manufacturer Sasol Wax. It has been chosen because of its viscosity and surface tension values, which are the two fuel parameters that are expected to have the biggest influence on the entrainment process (see also Fig. 1). Detailed laboratory experiments have been performed before, to measure these two parameters for the different fuels (see Sect. 2.2). All samples for the ballistic tests have been blackened by additives during fabrication to limit radiation effects during combustion to the fuel surface. 


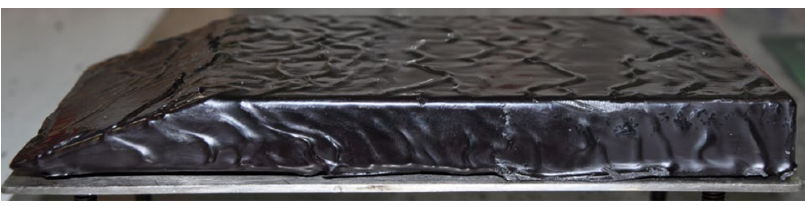

Fig. 3 Fuel slab configuration used in this research. Fuel sample after combustion test

Generally, the amount of blackening additive was less than $2 \%$ and has, therefore, negligible impact on the performance (Kobald et al. 2016). Three different percentages of a commonly available polymer have also been added to the paraffin samples, to have different viscosity values. In this way, it was possible to study the influence of this parameter on the entrainment process. Moreover, the addition of polymer increases the mechanical properties of the paraffin, thus increasing also the quality of the combustion visualizations (less polluted window). All the investigated fuel slabs have been manufactured with a $20^{\circ}$ forward facing ramp angle (see Fig. 3), due to the better flame holding and, consequently, higher flame quality.

\subsection{Paraffin-based fuels characterization}

Characterization of the paraffin samples is necessary, since the entrainment process strongly depends on the fuel properties. Analytical formula for material properties like surface tension and viscosity of paraffin waxes are available in different publications, such as Marano and Holder (1997a, b, c). Unfortunately, these are often only valid for straight paraffin with distinct carbon numbers. Therefore, they cannot be applied for most of the samples used in this research, as well as for paraffin-based mixtures.

Viscosity, liquid density and surface tension measurements of the four types of paraffin-based fuels used in this research were performed in the M3 chemical laboratory at the DLR Lampoldshausen.
The viscosity measurements were performed with the Thermo Haake Rheo stress 6000, which is a rotational rheometer with a cone-plate sensor. Early viscosity measurements at different shear rates showed that all the paraffin-based samples have a Newtonian behaviour, except for the paraffin with nanoclay particles (Kobald et al. 2017c). Therefore, the viscosity of the paraffin with polymer does not depend on the shear rate. Consequently, for these viscosity measurements, it was decided to take a constant shear rate of $2001 / \mathrm{s}$ and to vary only the temperature. The measurements of the viscosity of the samples at different temperatures are shown in Fig. 4. Each curve represents the average of four curves obtained for each fuel formulation. The standard deviation is around $10 \%$ of the average values at each measurement point. It can be noticed that the viscosity increases with increasing polymer addiction. Moreover, with increasing temperature, the viscosities of the three blends tend to decrease faster than that of pure paraffin.

The surface tension and the liquid density were measured with the EasyDyne tensiometer. The measurements of the two properties of the samples at different temperatures are shown in Figs. 5 and 6. In this case, each point corresponds to one single measurement performed on different samples for each fuel formulation. The curves are the interpolation of those points. The standard deviation, given by the instrument, on the single points is less than $1 \%$ and the $R^{2}$ for the interpolation curves is ranging from 0.93 to 0.98 .

\section{Experimental set-up and methods}

\subsection{Test set-up and data acquisition}

The experimental tests were performed at the Institute of Space Propulsion at the DLR Lampoldshausen at the test complex M11. An already existing modular combustion chamber, used in the past to investigate the combustion behaviour of solid fuel ramjets, was adjusted and used for
Fig. 4 Viscosity of paraffin 6805 with different additives at a constant shear rate. Values are normalized to the 6805 viscosity value at $120^{\circ}$

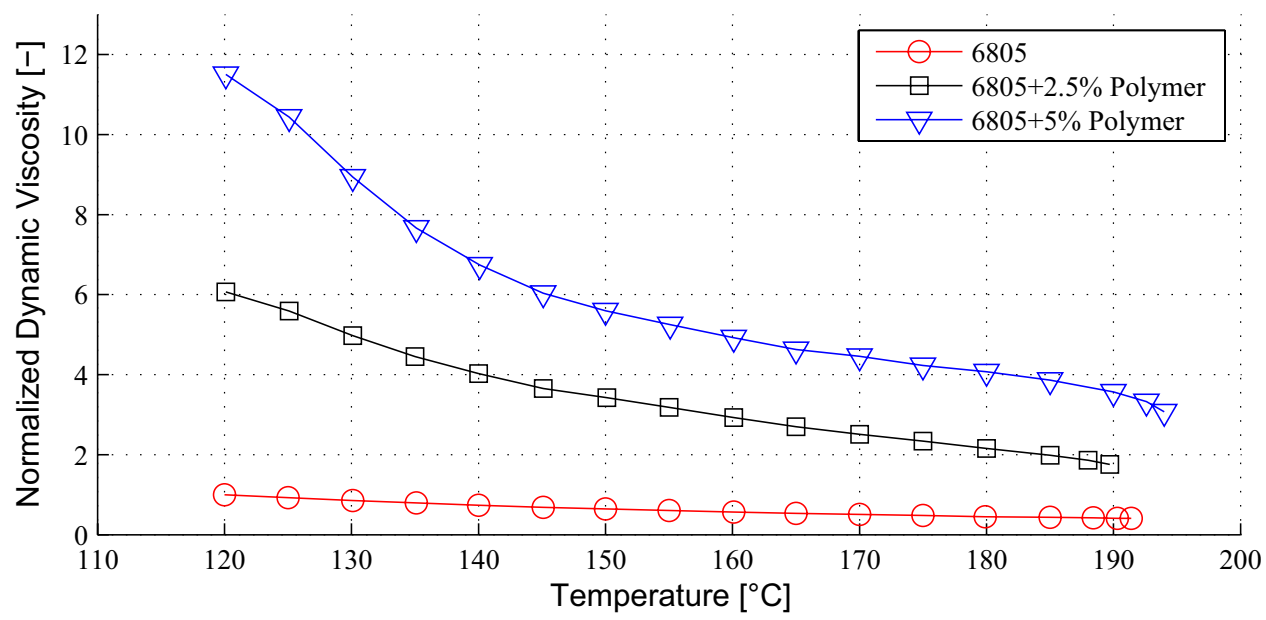


Fig. 5 Surface tension of paraffin 6805 with different additives. Values are normalized to the 6805 surface tension value at $80^{\circ}$
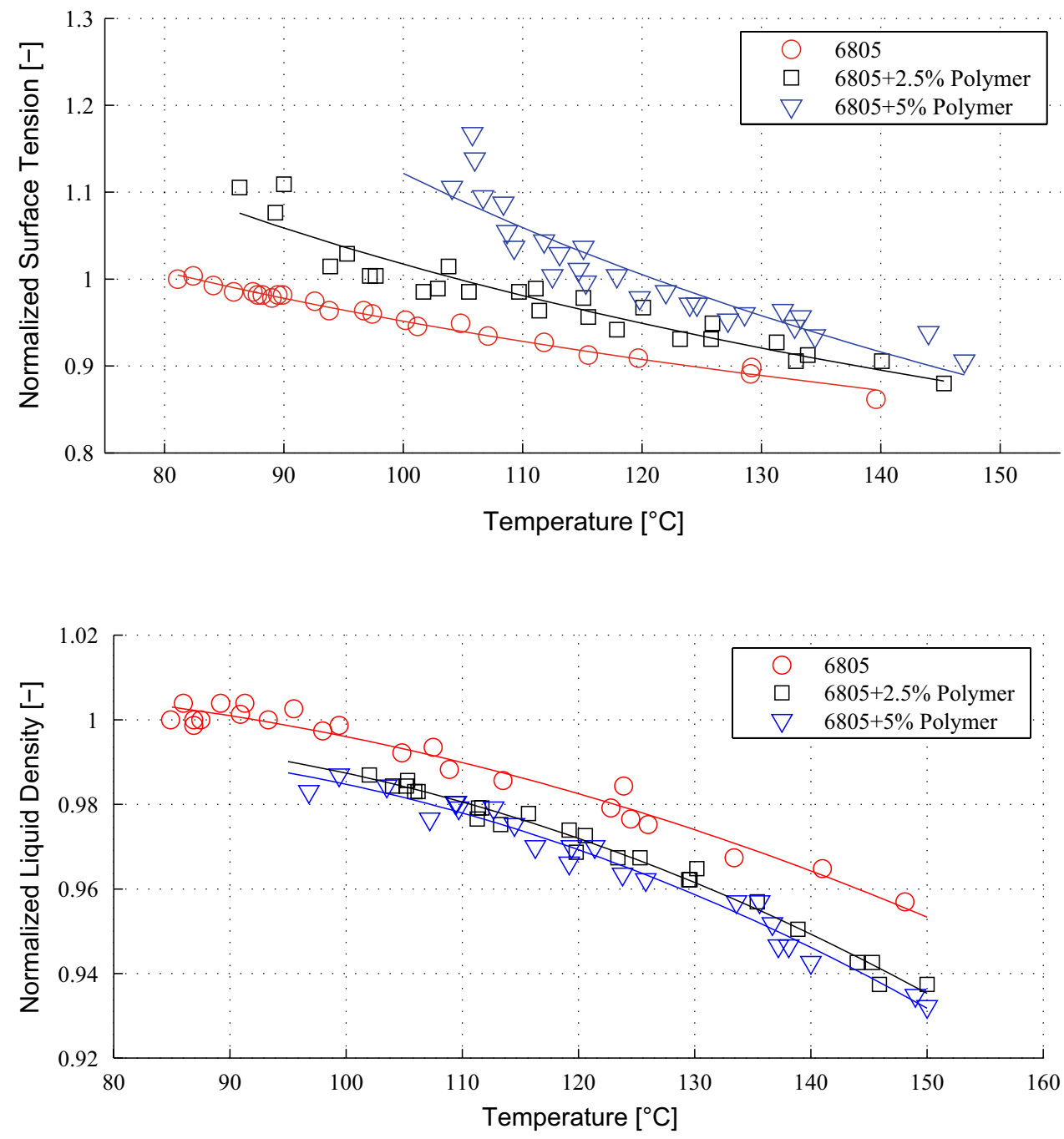

Fig. 6 Liquid density of paraffin 6805 with different additives. Values are normalized to the 6805 liquid density value at $85^{\circ}$ the test campaigns (Ciezki et al. 2003). With this set-up, it is possible to perform tests both with and without a facing step placed before the fuel grain, which provides adequate flame holding and assures combustion stability. Tests performed in the framework of this research were all done without the flame holding step. A side view of the whole combustion chamber set-up is shown in Fig. 7. The oxidizer flow is entering the combustion chamber from the left, after having passed two flow straighteners. Its mass flow rate is adjusted by a flow control valve and it is measured with a Coriolis flow meter. A high frequency static pressure sensor and a dynamic pressure sensor are mounted in the combustion chamber. Ignition is done via an oxygen/hydrogen torch igniter from the bottom of the chamber. The two windows at each side enable several different optical diagnostic tools. A test sequence is programmed before the test and is run automatically by the test bench control system. More details about the test bench and test settings are given in Kobald et al. (2013, 2015) and Petrarolo and Kobald (2016).

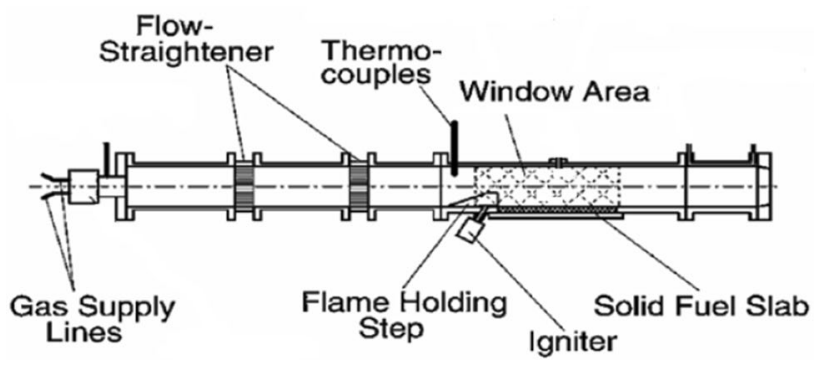

Fig. 7 Sideview of the combustion chamber set-up, adapted from Thumann and Ciezki (2002)

In the framework of this research, all tests were done at atmospheric pressure and with an oxidizer mass flow ranging from 10 to $120 \mathrm{~g} / \mathrm{s}$. Combustion tests were performed using a single-slab paraffin-based fuel in combination with gaseous oxygen. Burning time was $3 \mathrm{~s}$ for each test. For video data acquisition, a Photron Fastcam SA 1.1 high speed video camera was used with a resolution of $1024 \times$ 


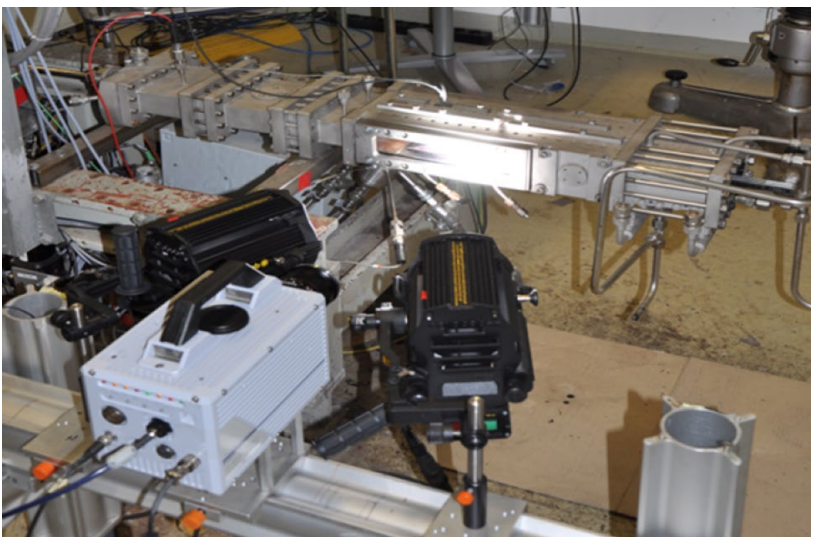

Fig. 8 Combustion chamber set-up with optical diagnostic

336 pixel. The frame rate, resolution and shutter time of the camera were adjusted for each test, according to the test conditions and position of the camera. A photo of the high speed video imaging set-up is shown in Fig. 8.

\subsection{Video analysis}

The combustion high speed videos are analysed with a Matlab ${ }^{\circledR}$ routine, which returns as results the most excited frequencies and wavelengths characterizing the liquid melt layer. The video analysis is divided into three main phases:

- video pre-processing, where the video is modified and the Snapshot Matrix is created;

- decomposition of the Snapshot Matrix with the two methods: POD (proper orthogonal decomposition) and ICA (independent component analysis);

- post-processing, where the power spectral density (PSD) of spatial and temporal coefficients is performed.

The video pre-processing steps are summarized in Fig. 9. A lot of efforts were put into finding the right settings and parameters that are needed in this really important and delicate phase of the video analysis. In the first step, the images are exported from the video and cropped with the Software VirtualDub. Usually filters are added, to adjust the brightness and the contrast of the images. The function sharpen is also used to enhance the contrast of adjacent elements. There exists also lateral burning at the sides of the fuel, so the bottom of the fuel is cropped just up to the solid liquid interface, to reduce noise and errors. Yet, the size of the area of interest is kept as large as possible to capture the flow dynamics on the whole upper surface of the fuel slab. The angled front and the rear end, where further vortices are created, are not included in the frames. It is important to underline that the analysed window has the same size in all the videos $(500 \times 60$ pixel $)$ and it is able to catch all the phenomena we are interested in, still leaving out sources of noise and errors (such as the aft and rear end of the slab and the bottom of the fuel). The images are then exported to MATLAB ${ }^{\circledR}$ and converted from true-colour RGB to binary data images, based on a luminance threshold. This allows us to work only with sparse matrices, thus saving computing time and space. The background noise, which usually consists of small light spots (most likely burning paraffin droplets), is removed, to better detect the flame edge. The thresholds for the binary conversion and for the background noise removal were accurately and manually chosen for each combustion operating condition, since the flame luminosity and the level of background noise and window pollution is different depending on the fuel composition and oxidizer mass flow. Still, before starting the automatic construction of the Snapshot Matrix, these parameters are always checked for few sample frames. Finally, to compute the excited frequencies and wavelengths, the waves edge is automatically detected with the "Canny" method and the data are saved in MATLAB $^{\circledR}$ as $2 D$ arrays. Each frame is then rearranged as a column vector and the Snapshot Matrix, which contains all the frames to analyse, is created. It has to be noticed that the recorded video data is a line of sight measurement. Thus, the data in the analysis represent an integrated measurement over the whole fuel slab width. This has to be taken into account when they are analysed.

In a second step, the Snapshot Matrix is decomposed with both algorithms, POD and ICA, into two matrices containing spatial and temporal coefficients. At the end, the power spectral density (PSD) of these coefficients is performed, to obtain the most excited frequencies and wavelengths during the combustion. Further details of the applied methods are given in Kobald et al. (2015) and Petrarolo and Kobald (2016).

\section{Theoretical background: decomposition methods}

\subsection{Proper orthogonal decomposition}

The proper orthogonal decomposition (POD) or principal component analysis (PCA) has been used in diverse area of research to obtain approximate, low-dimensional descriptions of turbulent fluid flows, structural vibrations and dynamical systems. It has also been extensively used in image processing, signal analysis and data compression (Chatterjee 2000).

The POD is a statistical method where an orthogonal transformation is used to convert a set of data into a set of linearly uncorrelated variables, which are called principal components. Their number is usually less than the number of the original variables. An orthogonal transformation to the basis of the eigenvectors of the sample covariance matrix 
Fig. 9 Video data pre-processing steps
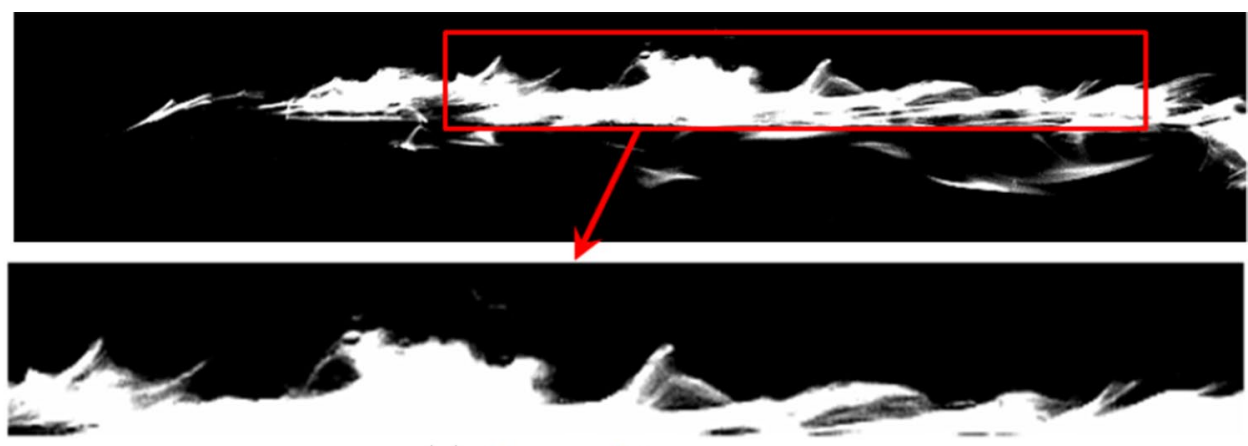

(a) Cropped image

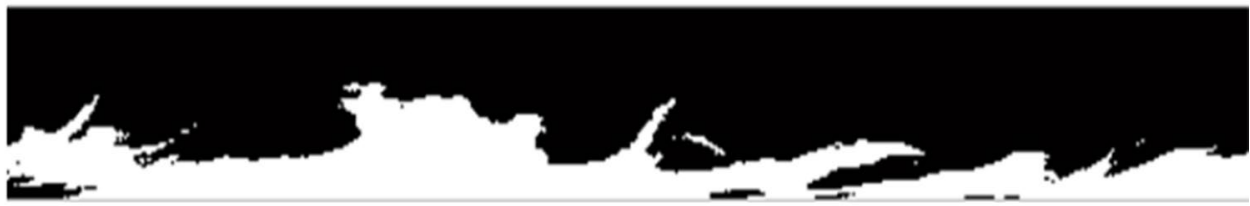

(b) Binary conversion

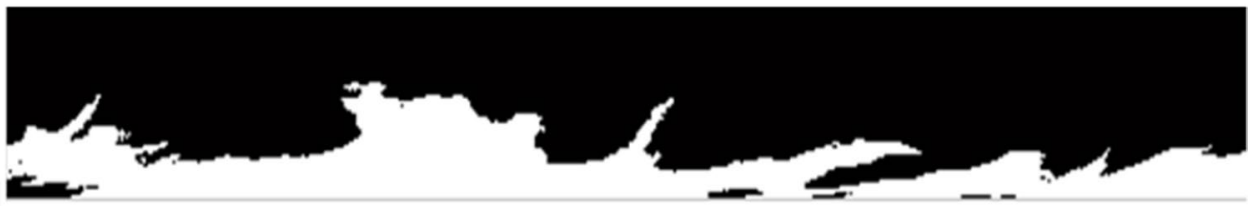

(c) Background noise removal

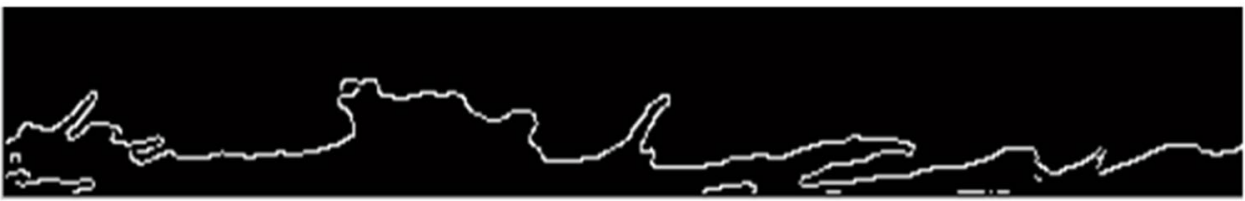

(d) Edge detection

is performed and the data are projected onto the subspace spanned by the eigenvectors corresponding to the largest eigenvalues (most energetic modes). So, POD gives an orthogonal basis that ranks modes according to an energy criterion (Kerschen et al. 2005). This enables us to retain only the dominant modes and to filter out the presence of the measurement noise, thus providing a good characterization of the dynamics of the problem. Finally, POD is able to explicitly separate the spatial and time information (Risvik 2007). On the other hand, the linear nature of the method can be a restriction for some data sets. Moreover, since POD removes linear correlations among variables, it is only sensitive to second-order statics. This means that this method is able to find only uncorrelated variables (Risvik 2007).

In the present work, the POD is applied to the analysis of the luminosity field of images (scalar field) in a reactive flow. This allows for an analysis of the considered scalar field by decomposing it into mean, coherent and incoherent parts via statistical methods and to visualize the relevant morphologies. In general, the coherent part includes all fluctuations possessing a somehow structured feature over the burning process. The incoherent part includes all fluctuations for which no pattern can be identified over the burning process. It is commonly thought that the first few modes correspond to the average structure of the data, while higher order modes contain information about fluctuations (Geladi and Kowalski 1986). The nonlinear iterative partial least squares (NIPALS) algorithm is used for the principal component analysis in the POD method. The power spectral density (PSD) of the temporal and spatial coefficients is performed at the end of the algorithm to obtain the excited frequencies and wavelengths during the combustion.

\subsection{Independent component analysis}

The independent component analysis (ICA) is a statistical signal processing technique whose main applications are blind source separation, blind deconvolution and feature extraction (Hyvarinen 1997). One application with combustion was demonstrated by Bizon et al. (2013b, 2013a). They 
(a)
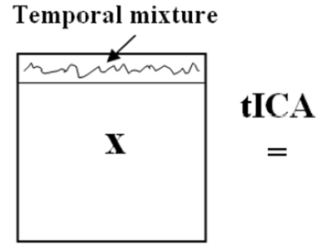

Image mixture
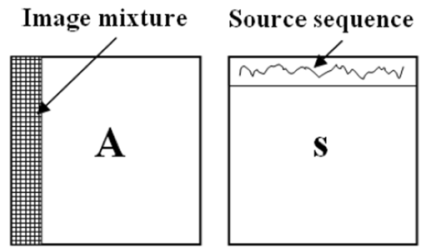

(b)
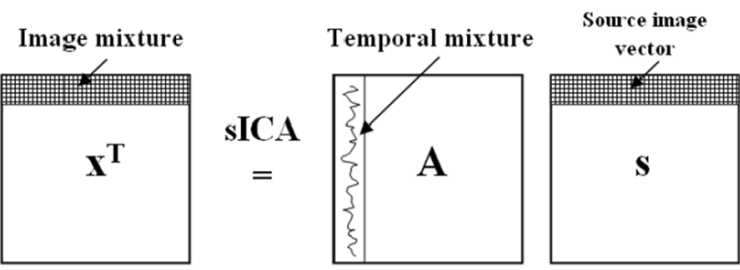

Fig. 10 Vector matrix representation of the mixing process for tICA and sICA, taken from Stone (2004)

applied ICA to 2D images of combustion-related luminosity, to identify leading independent structures.

The ICA is a statistical and computational technique for revealing hidden components that underlie the observed data. The latent variables are assumed to be non-Gaussian and mutually independent in space and/or time: they are called the independent components of the observed data. The transformed variables correspond to the underlying components that describe the essential structure of the data and that correspond to some physical causes involved in the process.

The ICA is a much more powerful method with respect to the POD. The basis functions found by the POD, which reflect the directions of the most prominent variances in the data, are uncorrelated but not statistically independent. This means that higher order dependencies still exist and, therefore, they are not properly separated. In other words, all POD modes contain some elements of all structures found in all of the fields (Bizon et al. 2013b). On the other hand, ICA is able to search for basis functions that are statistically independent or as independent as possible, increasing the independence to higher statistical orders. When deriving these components, the data are separated into either spatially (sICA) or temporally (tICA) independent components; each choice yields corresponding statistically independent images or time courses, see also Fig. 10.

Some weak points have to be highlighted also for ICA: unlike for the principal components of the data, which are ordered according to their variance, no intrinsic order exists for the independent components. Moreover, ICA provides a solution only up to a multiplicative constant. In other words, the order, the signs and the scaling of the independent components cannot be determined: indeterminacy is an inherent property of this analysis (Hyvarinen and Oja 2000).

The aim of the present work is to identify independent spatial structures evolving in time. Therefore, the spatial
ICA is applied to the analysis of the luminosity field of the combustion process in a hybrid engine. This allows the identification of the leading independent structures during the burning process. The FastICA algorithm (Hyvarinen and Oja 2000) is employed. The power spectral density (PSD) of the temporal and spatial coefficients is performed at the end of the algorithm to obtain the excited frequencies and wavelengths during the combustion.

\section{Kelvin-Helmholtz instability}

The Kelvin-Helmholtz instability (KHI) is an instability that arises in parallel shear flows where a discontinuity in velocity is present. The entrainment mechanism is dominated by the KHI behaviour. The onset of KHI, which depends on the Reynolds number based on the liquid properties, is a necessary condition for droplets entrainment. The unstable waves then break up into droplets by the Plateu-Rayleigh instability mechanism (primary break up). Droplets entrainment occurs from the unstable waves, when the interfacial shear force between the two fluids exceeds the retaining force of surface tension (Ishii and Grolmes 1975; Kuo and Houim 2011). Droplets are then accelerated by the main gas flow and break up into smaller droplets or rebound. This mechanism is also referred as secondary instability (see Fig. 11).

In this work, the stability of a stratified gas-liquid flow is studied in a 2D domain for a horizontal channel configuration (Funada and Joseph 2001). According to the Squire's Theorem, a two dimensional system is always more unstable than any equivalent three dimensional system. This means that KHI can be fully described and analysed using a 2D domain. The model used in this analysis is shown in Fig. 12. The coordinate $y$ was neglected, so that a 2D bounded model could be studied.

The governing equations used for describing the KHI problem are the Navier-Stokes and the continuity equations for viscous Newtonian fluids. The fuel liquid layer is considered at rest and the combustion products gas flow is moving at a fixed velocity. The only considered external force is the gravitational one. The effect of viscosity on shear stress is neglected and both fluids are considered homogeneous and irrotational. The equations are linearized and sinusoidal solutions are applied (Kobald et al. 2015). A small sinusoidal perturbation $h$ is introduced at the interface between the gas and the liquid:

$h(x, t)=B \mathrm{e}^{\mathrm{ikx}-\mathrm{iwt}}$

Here the complex wave frequency $\omega$ gives information about the temporal stability, while the complex wave number $k$ gives information about the spatial stability. For $\omega_{\mathrm{I}}=0$ neutral temporal stability is achieved, $\omega_{\mathrm{I}}>0$ indicates temporal instability, while $\omega_{\mathrm{I}}<0$ indicates temporal stability. In the 
Fig. 11 Kelvin-Helmholtz instability, taken from Pelletier (2009)
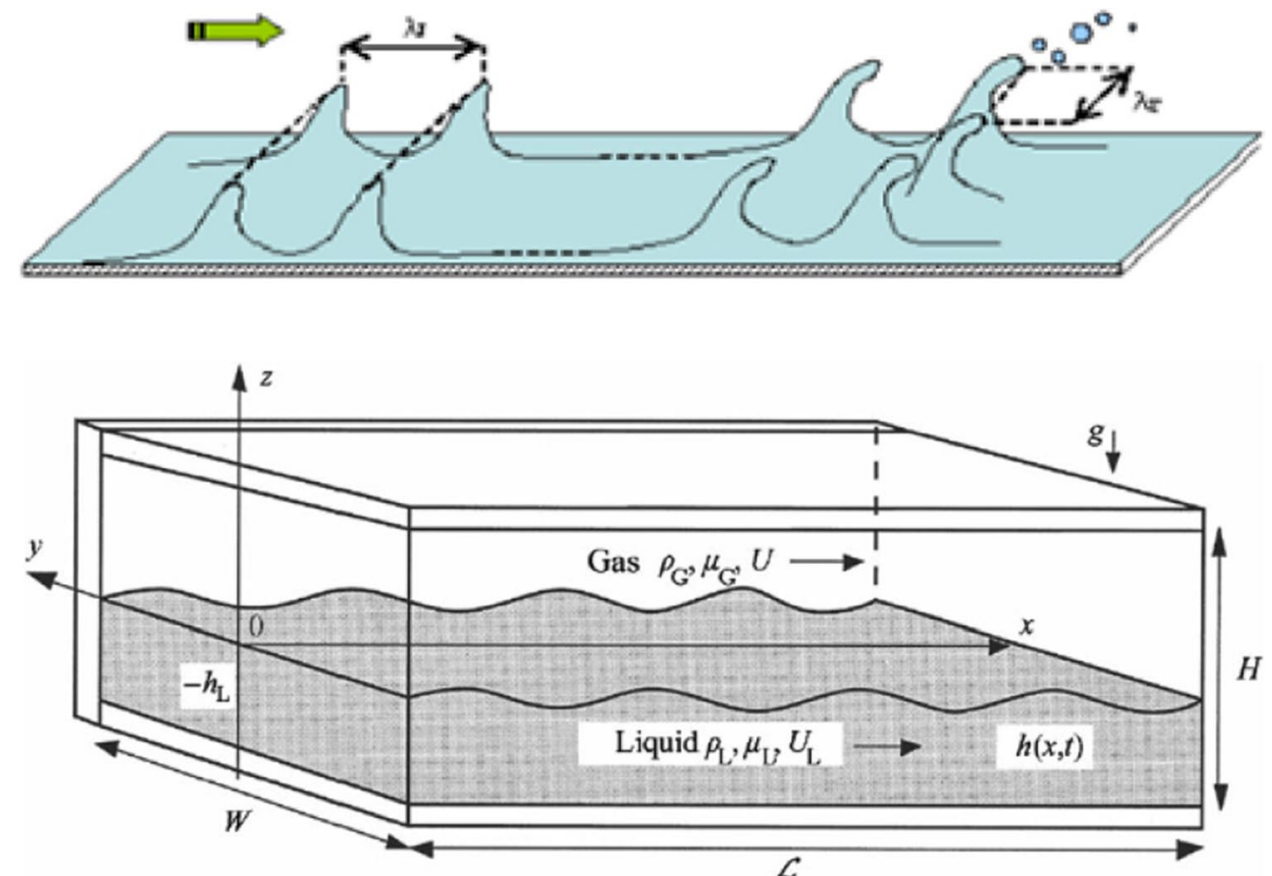

Fig. 12 Kelvin-Helmholtz instability bounded model, adapted from Funada and Joseph (2001) same way, we get spatial instability for $k_{\mathrm{I}}<0$, stability for $k_{\mathrm{I}}>0$ and neutral stability for $k_{\mathrm{I}}=0$.

Solving the equations leads to the dispersion relation:

$K_{0} \omega^{2}+2 K_{1} \omega+K_{2}=0$

with $K_{0}=a_{\mathrm{G}} \rho_{\mathrm{G}}+a_{\mathrm{L}} \rho_{\mathrm{L}} ; K_{1}=-k U a_{\mathrm{G}} \rho_{\mathrm{G}}+i k^{2}\left(a_{\mathrm{G}} \mu_{\mathrm{G}}+a_{\mathrm{L}}\right.$ $\left.\mu_{\mathrm{L}}\right) ; K_{2}=\left[U^{2} k^{2} a_{\mathrm{G}} \rho_{\mathrm{G}}-k g\left(\rho_{\mathrm{L}}-\rho_{\mathrm{G}}\right)-\gamma k^{3}\right]$.

To find the neutral curve, we need to search for those values of the parameters for which the roots of the dispersion relation (2) are real (note that $\omega=\omega_{\mathrm{R}}+i \omega_{\mathrm{I}}$ ). By manipulating the dispersion relation and solving it with respect to the gas flow speed $U$, the neutral curve is obtained:

$U^{2}=g \frac{\left(a_{\mathrm{L}} \mu_{\mathrm{L}}+a_{\mathrm{G}} \mu_{\mathrm{G}}\right)^{2}}{a_{\mathrm{L}} a_{\mathrm{G}}{ }^{2} \mu_{\mathrm{G}}{ }^{2}+\rho a_{\mathrm{G}} a_{\mathrm{L}}{ }^{2} \mu_{\mathrm{L}}{ }^{2}}\left(\beta^{2} k+\frac{1-\rho}{k}\right)$

with $a_{\mathrm{L}}=\operatorname{coth}\left(k h_{\mathrm{L}}\right) ; a_{\mathrm{G}}=\operatorname{coth}\left(k h_{\mathrm{G}}\right) ; \rho=\frac{\rho_{\mathrm{G}}}{\rho_{\mathrm{L}}} ; \beta=\sqrt{\frac{\gamma}{g \rho_{\mathrm{L}}}}$

Figure 13 shows the neutral curves for pure paraffin 6805 at different mixture ratios OF (ratio between oxidizer and fuel mass flow rate). The values of liquid fuel density, surface tension and viscosity are taken from the measurements done in the chemical laboratory (see Sect. 2.2). A liquid layer temperature of around $300{ }^{\circ} \mathrm{C}$ is considered (averaged temperature between melting and boiling points). The gas density and viscosity values at each mixture ratio OF are given by the software NASA chemical equilibrium with applications (CEA) at optimum conditions. ${ }^{1}$ The local minimum of each curve shows the critical wave number and

\footnotetext{
${ }^{1}$ See also: https://www.grc.nasa.gov/www/CEAWeb/.
}

corresponding critical gas velocity. The critical wavelength is the first unstable wave that is excited and it appears when the critical gas speed is reached. For gas speed below the critical one, no instability is achieved. The critical values are influenced by the liquid viscosity (see Fig. 14).

\section{Results and discussion}

In this paper, the influence of the oxidizer mass flow and fuel viscosity on the entrainment process is discussed. These are the two parameters that are expected to have the biggest influence on the droplets entrainment process, as shown in Fig. 1 (the oxidizer mass flow is not explicitly included in the arguments of the equation in Fig. 1, but it is influencing the entrainment mass flow through the dynamic pressure, with flow density and speed). Therefore, two main test campaigns were performed: pure paraffin 6805 and the same paraffin with $5 \%$ polymer were analysed with an oxidizer mass flow varying in a range from 10 to $120 \mathrm{~g} / \mathrm{s}$. In a previous test campaign (Petrarolo et al. 2017), the influence of the forward facing ramp of the fuel slab was investigated with a fixed oxidizer mass flow and the main frequencies and wavelengths characterizing the entrainment process were identified. Therefore, in these test campaigns, it was possible to study the influence of the fuel viscosity and oxidizer mass flow on the liquid layer break up process, independently from the fuel configuration. Fuel slabs with $20^{\circ}$ forward facing ramp were used, due to the better flame quality (i.e., better flame holding and continuous flame front). 
Fig. 13 Neutral curve of pure 6805. For each OF, the unstable region is for speeds above the corresponding curve; the stable region is below each curve

Fig. 14 Influence of OF and fuel viscosity on the critical gas speed and analysed, as explained in Sect. 3. By analysing the PSD results of both POD and ICA, it is possible to obtain the most excited frequencies and wavelengths for each of them. POD enables the recognition of the main energetic structures of the flow field, ICA identifies the leading independent
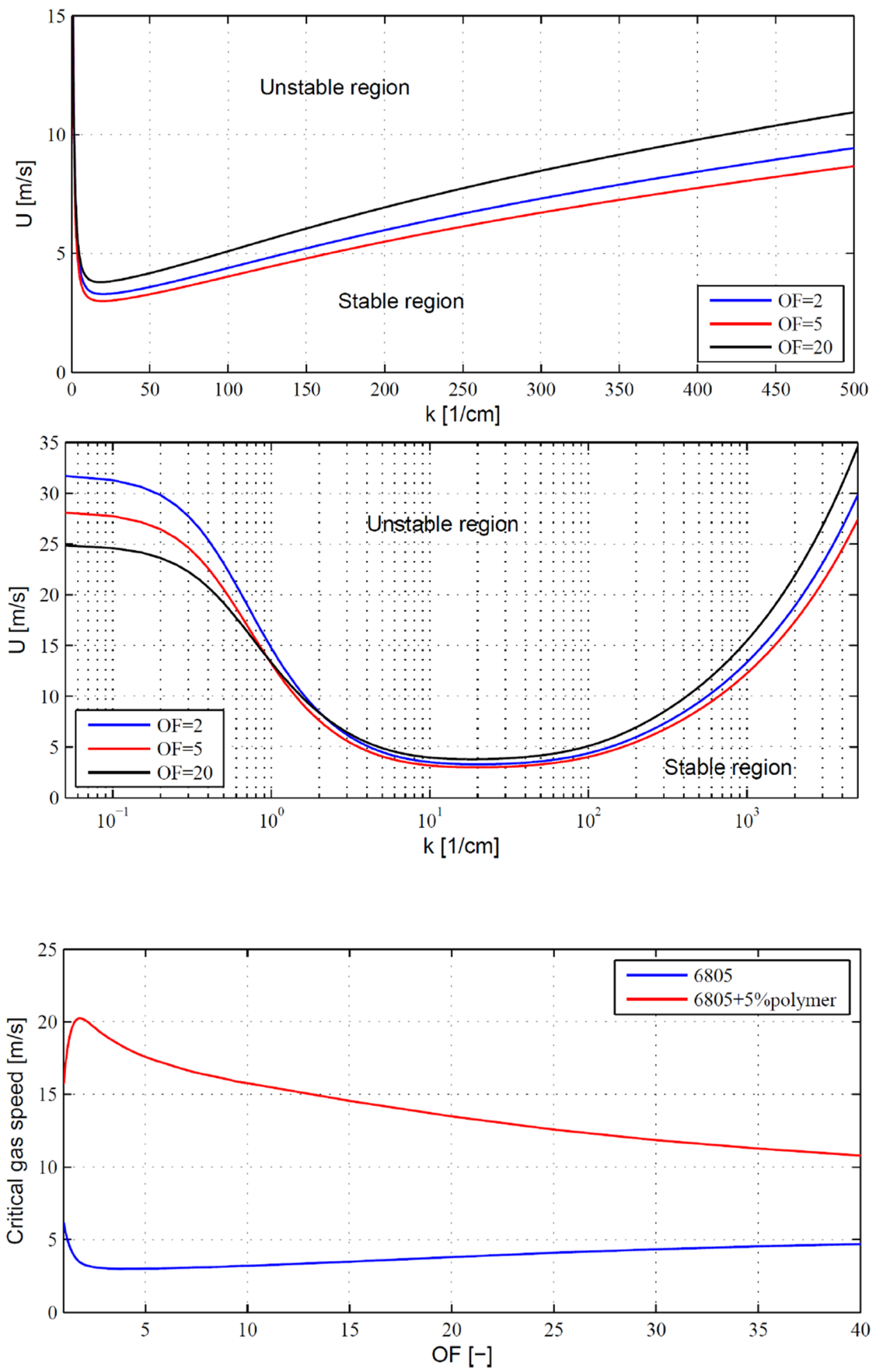

structures underlying the data. It is important to underline that, to better characterize the dynamic of the process, a combination of the two decomposition techniques was necessary. In fact, both methods yield a whole range of different frequencies and wavelengths, which are amplified during the combustion. Some of them are related to the main dynamics 
Fig. 15 Dependency of the KHI frequencies on the fuel viscosity and oxidizer mass flow
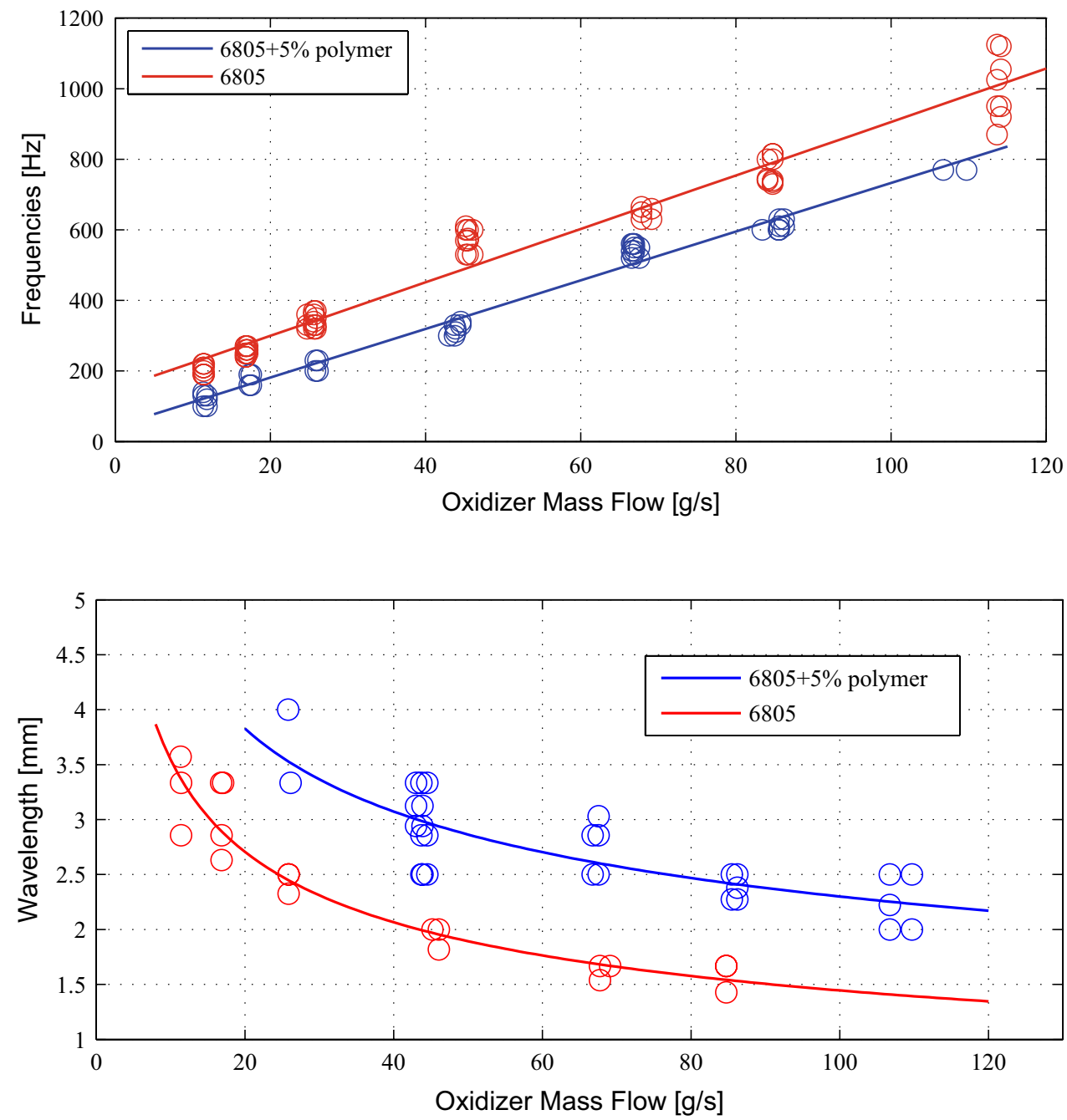

Fig. 16 Dependency of the KHI longitudinal wavelengths on the fuel viscosity and oxidizer mass flow of the combustion process, others are just random appearing vortices or not so energetic periodic signal (such as noise). To understand which frequencies and wavelengths are actually related to the main combustion events, it was necessary to compare the results of the two methods. If a frequency peak appears only in the POD, this is most likely related to a random energetic vortex (POD recognizes the most energetic structures in the flow field). On the other hand, if a frequency peak appears only in the ICA, this is most likely a periodic but not energetic signal, so not important (ICA recognizes periodic independent structures). Those peaks which appear in both methods are periodic and energetic signals, so related to the main events during the combustion process. So, at the end, only those frequency and wavelength peaks appearing in both methods were considered. The analysis was carried out on $1 \mathrm{~s}$ (10,000 frames) during the steadystate. Frequency and wavelength peaks were taken for each fuel formulation and oxidizer mass flow and then compared.
The results show that the combustion is dominated by wavelike structures and that the most excited frequencies and wavelengths characterizing the liquid melt layer depend on the fuel viscosity and oxidizer mass flow, see Figs. 15 and 16. Nevertheless, some limitations have to be taken into account when the results are analysed. First of all, the analysis is performed on 2D images. This means that what we analysed can be the superposition of all the combustion phenomena appearing on the fuel surface along the whole width. Furthermore, the waves on the fuel surface do not probably move straight in the horizontal direction. Moreover, the brightness of the flame and the condensed products which polluted the window increase the complexity of the optical measurement. Finally, it has to be highlighted that at the base of the whole analysis there is the assumption that the flame front ${ }^{2}$ follows the liquid layer. This is the reason why it is assumed that the waves appearing on the flame correspond to the waves of the liquid layer.

\footnotetext{
${ }^{2}$ In a diffusion flame, the term flame front indicates the thin interface separating the fuel-rich area from the oxidizer-rich one. It is used for indicating the region where the combustion reactions take place.
} 
Fig. 17 Critical gas speed curves with experimental values for 6805 (top) and 6805+5\% polymer (bottom)
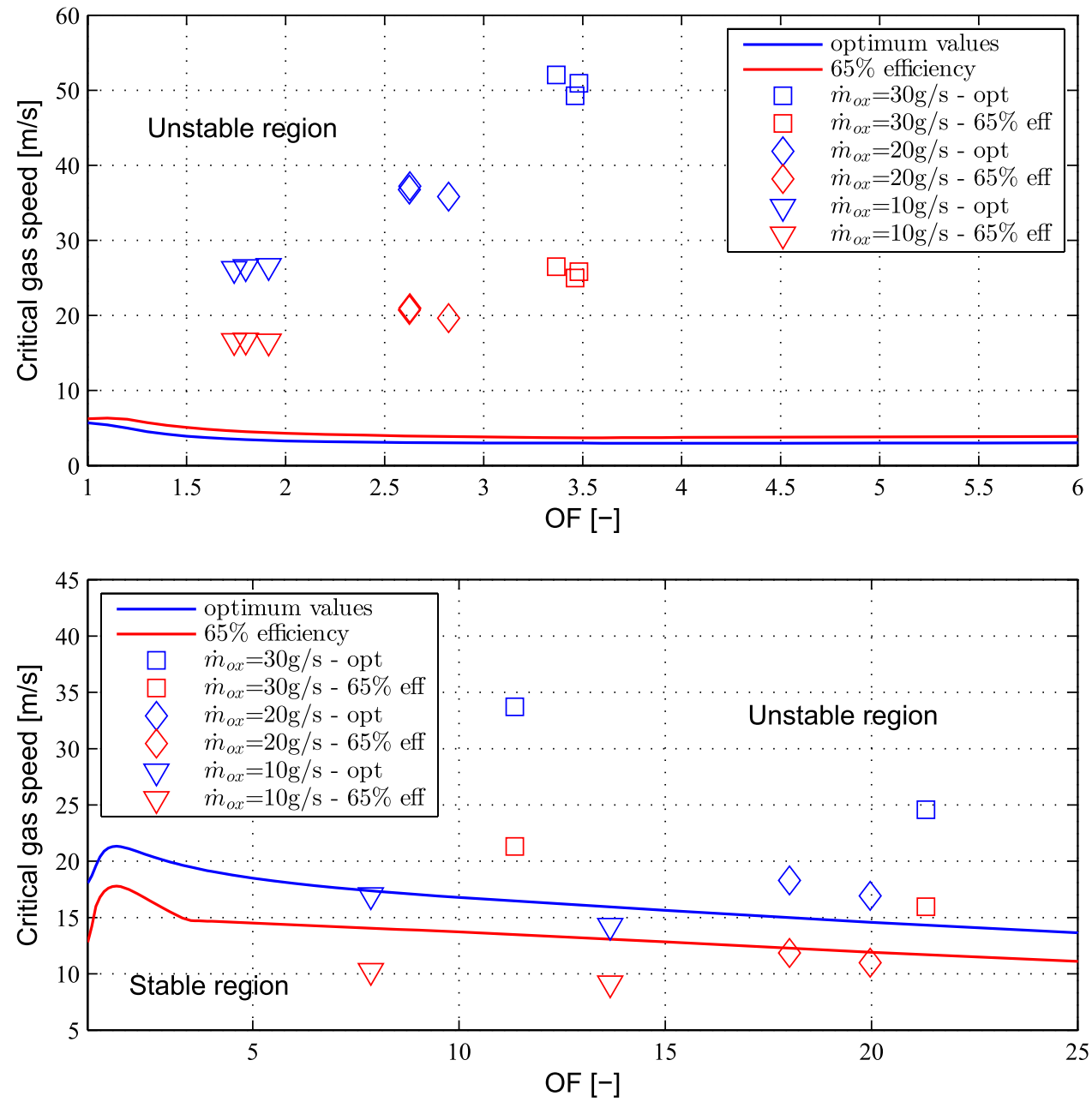

\subsection{Fuel viscosity}

From what concerns the fuel viscosity, it is possible to notice that the most excited frequency values at the same oxidizer mass flow become lower as the viscosity increases. On the other hand, the longitudinal wavelengths become longer in the formulation with the polymer addition. So, the amplified frequency and wavelength values connected to the KHI are influenced by the liquid viscosity, as expected from the entrainment (Karabeyoglu et al. 2002; Karabeyoglu and Cantwell 2002) and Kelvin-Helmholtz (Funada and Joseph 2001) theories. In particular, by increasing the viscosity the frequency values decrease and the longitudinal wavelengths increase. This means that the higher the viscosity, the more stable the liquid layer is. This leads to a lower number of released and, consequently, entrained droplets and so to a lower regression rate.

\subsection{Oxidizer mass flow}

For what concerns the oxidizer mass flow, the values of the excited frequencies become higher as the oxidizer mass flow increases, while the excited longitudinal wavelengths become smaller. Both fuel viscosities show the same trend. Moreover, for very low mass flows, no distinct wavelength peaks are detected with both decomposition methods for the fuels with higher viscosity. This is in agreement with the Kelvin-Helmholtz instability model. The very low oxidizer mass flows had a speed below the critical one that is needed to achieve instability (Funada and Joseph 2001). This is clearly visible in Figs. 17 and 18. In Fig. 17, it is possible to see the experimental gas flow speeds at different oxidizer mass flows, computed both at optimum conditions and at $65 \%$ efficiency for the two fuel formulations. The two curves represent the critical gas speed according to KHI theory, computed considering optimum conditions and $65 \%$ efficiency. Here it is possible to notice that for the pure paraffin, the gas speeds for every mass flow are all in the unstable region, considering both conditions. On the other hand, for the formulation with the polymer addition, the gas speeds connected with the lower mass flows are in the stable region, so below the critical speeds needed to achieve the instability. The same consideration can also be done by looking at Fig. 18. Here the critical gas mass flows computed at 
Fig. 18 Critical mass flow curves with experimental values for 6805 (top) and $6805+5 \%$ polymer (bottom)
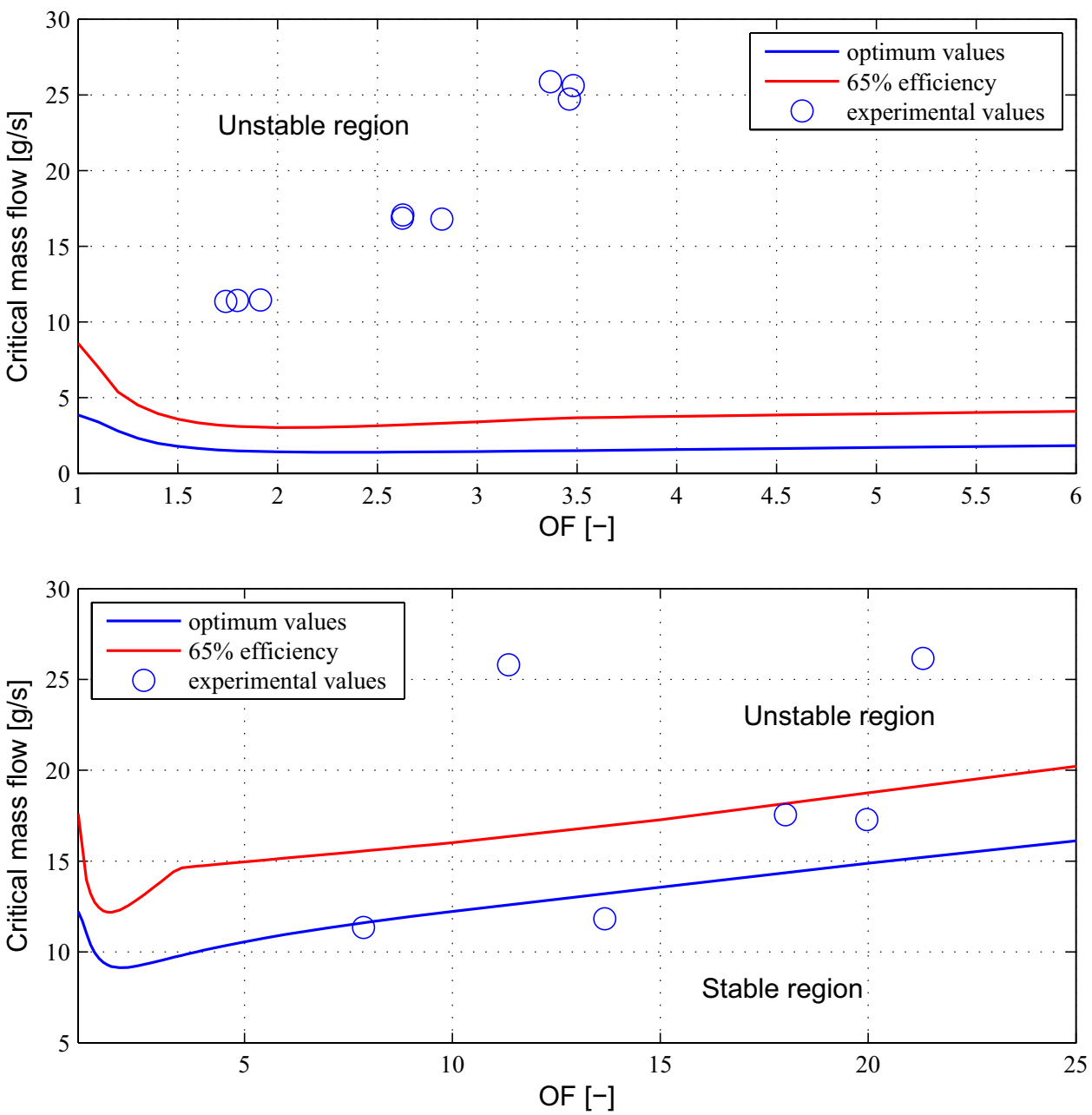

optimum conditions and $65 \%$ efficiency are plotted versus the mixture ratios. The experimental oxidizer mass flows with the respective OFs are also shown. Also in these plots, it can be seen that for the pure paraffin, all the experimental values are in the unstable area. On the contrary, for the fuel blend, the tests with the lowest mass flows are in the stable zone. Moreover, from both figures, it can be noticed that the critical gas speed and mass flows for the pure paraffin are lower than those for the paraffin with polymer addition. This means that the stability limit is lower, and consequently easier to achieve, for fuels with lower viscosity (as already shown in Fig. 14). Finally, it can be also seen that, by decreasing the combustion efficiency, the critical mass flows are increasing, so increasing the stability limit.

As already seen in Sect. 5, the critical speed depends on the liquid layer viscosity: the higher the viscosity, the higher its damping effect on the waves and, consequently, the higher the critical speed is. This is the reason why, for the pure paraffin samples, it is still possible to detect waves at $\dot{m}_{\mathrm{Ox}} \simeq 10 \mathrm{~g} / \mathrm{s}$, while with $6805+5 \%$ polymer (which has a higher viscosity) the last detectable waves are at $\dot{m}_{\mathrm{Ox}} \simeq 25 \mathrm{~g} / \mathrm{s}$. This means that the critical speed for the pure paraffin is lower than that of the same paraffin with 5\% polymer (see also Fig. 14) and, consequently, the range of unstable waves is also wider for 6805 with respect to the blend. So, at flow speeds below the critical one, the disturbances of the liquid layer are damped by the liquid viscosity. On the other hand, at flow speeds above the critical one the same disturbances are able to produce waves which grow. In this way, a range of wavelength is excited and the wavelength having the highest growth rate ultimately dominates. Moreover, at oxidizer mass flows just above the critical speed, longer waves (around 1-2 cm) are mostly appearing. These waves tend to be stable since their phase speed is higher and, thus, the relative flow speed for a given mass flow is lower. On the other hand, viscous damping in the liquid dominates the very shortest waves, making them stable. Therefore, only waves with an intermediate range of wavelengths may be unstable (see also Fig. 13).

Frame images taken from the recorded combustion videos are shown in Fig. 19. They show the combustion flame of the paraffin blend at very low, intermediate and very high oxidizer mass flows. The frames are taken at the same point in time, around $2 \mathrm{~s}$ after the ignition. Thus, they all show a steady-state combustion flame. From these images, it can be 
Fig. 19 Combustion flame of $6805+5 \%$ polymer with $\dot{m}_{\mathrm{Ox}}=10 \mathrm{~g} / \mathrm{s}, \dot{m}_{\mathrm{Ox}}=50 \mathrm{~g} / \mathrm{s}$, $\dot{m}_{\text {Ox }}=120 \mathrm{~g} / \mathrm{s}$ (from top to bottom) created within this research (oxidizer mass flow from left to right)
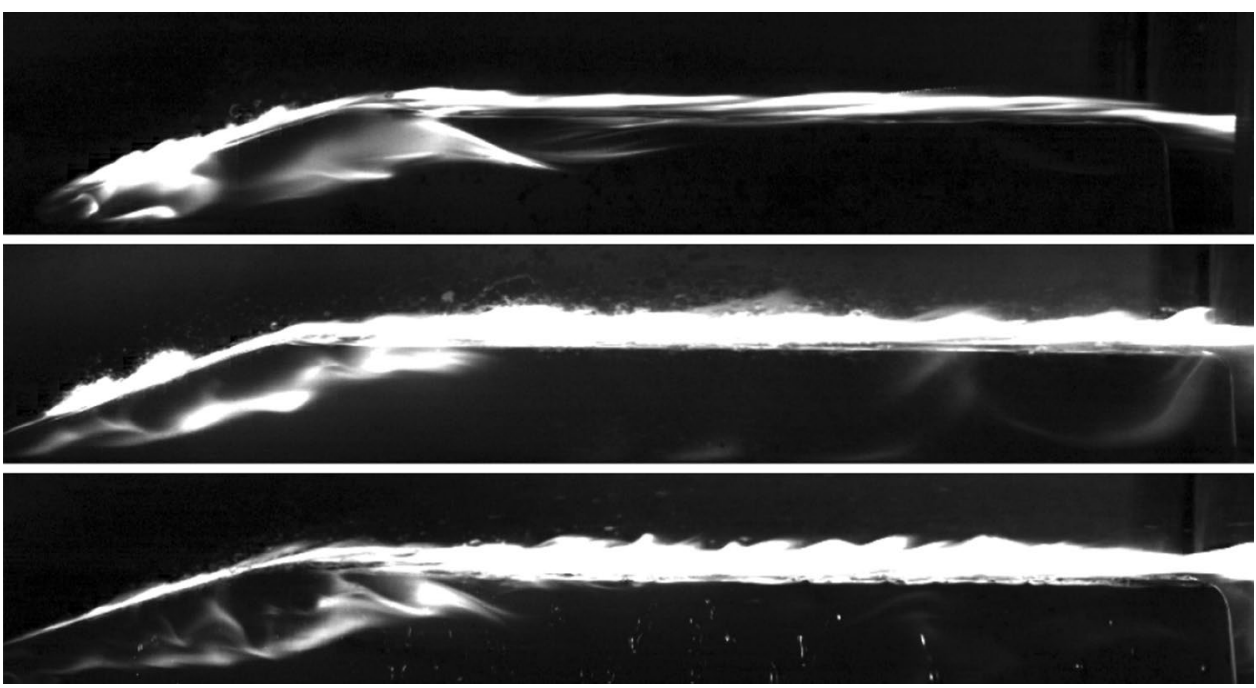

noticed the difference in the flame stability for the different mass flows. In the test with $\dot{m}_{\mathrm{Ox}}=10 \mathrm{~g} / \mathrm{s}$, the flame appears to be more flat, with some points of local extinction especially in the rear of the fuel slab, where the flame appears to be made up of elongated filaments. The dynamics of the processes in the combustion chamber is slower and the turbulence level is lower. In the case with $\dot{m}_{\text {Ox }}=120 \mathrm{~g} / \mathrm{s}$, many short waves appear on the flame surface and the typical shape of Kelvin-Helmholtz waves can be recognized in some of them. The flame is burning continuously along the fuel surface with no points of local extinction. The process dynamics is faster and the turbulence is higher. Finally, in the combustion tests at $\dot{m}_{\mathrm{Ox}}=50 \mathrm{~g} / \mathrm{s}$ waves can be seen on the flame front, but they are longer with respect to the case with higher mass flow and they seem to be more stable. Still, typical Kelvin-Helmholtz waves can be seen, like in this frame at the rear of the fuel slab. The flame front is continuous, without point of local extinction and well-attached to the fuel surface.

It can also be noticed that the flame sheet becomes thicker as the oxidizer mass flow increases. This is due to the increased convection and turbulence level in the boundary layer, which causes an increase in the heat exchanges rate between the fuel and the gas flow. As a result, the melting and evaporation rates of the liquid layer increase, thus causing an increase in the blowing of fuel vapours from the fuel surface to the flame. This, in turn, produces an increase in the boundary layer thickness and in the instability of the liquid layer.

\section{Conclusion}

The combustion behaviour of different paraffin-based 2D fuel slab samples burning with GOX was investigated with an optical combustion chamber. High speed video imaging enables the collection of a huge amount of data, which needs to be analysed in detail. Therefore, two automated data evaluation techniques, based on POD and ICA, were applied to the analysis of the luminosity field of images in a reactive flow. This allows for an analysis of the considered scalar field by identifying leading components during the burning process. POD and ICA were applied separately to the same luminosity data. The results obtained prove the robustness of the two decomposition methods and the effectiveness of the video analysis process. It was shown that the combustion of paraffin-based hybrid rocket fuels is dominated by wave-like structures and that the most excited frequencies and wavelengths characterizing the liquid melt layer depend on the fuel viscosity and oxidizer mass flow. This is important to better understand the onset and development of the entrainment process, which is connected to the amplification of longitudinal unstable waves caused by the high velocity gas flow over the fuel surface.

Two main test campaigns were performed with two different fuel compositions: pure paraffin 6805 and the same paraffin with $5 \%$ polymer. Fuel slabs with $20^{\circ}$ forward facing ramp were used, due to the better flame holding and continuous flame front. In both test campaigns, the oxidizer mass flow was varied in a range from 10 to 120 $\mathrm{g} / \mathrm{s}$. From the results, it is shown that the fuel viscosity influences the most amplified frequencies and longitudinal wavelengths connected to the liquid layer instability process. In particular, the higher the viscosity, the lower the values of the excited frequencies and the longer the longitudinal waves. This means that the higher the viscosity, the more stable the liquid layer. Moreover, a dependency of the instability process on the oxidizer mass flow was also found. In this case, the values of the excited frequencies become higher as the oxidizer mass flow increases, while the excited longitudinal wavelengths become smaller. Both fuel viscosities show the same trend. For very low mass flows, no distinct wavelength peaks are detected for the 
paraffin blend fuels. This is due to the fact that, at very low oxidizer mass flows, the flow speed is below the critical one that is needed to achieve instability. The two fuel formulations have different critical speed, due to their different viscosity values: the critical speed for the pure paraffin is lower than that of the same paraffin with $5 \%$ polymer and, consequently, the range of unstable waves is also wider for 6805 with respect to the blend. A comparison of the experimental results with the neutral curves coming from the KHI model was performed. Here it is clearly shown that all the experimental values for pure paraffin are in the unstable region. On the other hand, for the paraffin with $5 \%$ polymer the experimental values connected to the lower mass flows ( $\dot{m}_{\mathrm{Ox}} \simeq 10-20 \mathrm{~g} / \mathrm{s}$ ) are below the neutral curve and, consequently, in the stable zone.

The finding of a dependence between the oxidizer mass flow and the Kelvin-Helmholtz frequencies and wavelengths brought to the demonstration that the fuel regression rate (droplets entrainment rate) is directly connected to the liquid layer instability process. In fact, from the hybrid rocket combustion theory (Marxman et al. 1963; Marxman and Gilbert 1963), it is known that the regression rate is connected to the oxidizer mass flux $G_{\mathrm{Ox}}$, through the law $r_{\mathrm{f}}=a G_{\mathrm{Ox}}{ }^{n}$. The parameters $a$ and $n$ depend on the propellants formulation and were determined experimentally in the framework of this research for the used fuel formulations. The oxidizer mass flux is defined as $G_{\mathrm{Ox}}=\frac{\dot{m}_{\mathrm{Ox}}}{A_{\text {cross }}}$, where $A_{\text {cross }}$ is the area crossed by the oxidizer mass flow during the combustion process, which, in the case of a fuel slab, is almost constant. At this point, the connection between the regression rate of the fuel slab and the excited frequencies and wavelengths of the liquid layer is straightforward, since they both depend on the oxidizer mass flow [(see also Petrarolo et al. (2017)].

To the author's knowledge, this is the first case in literature that proved the connection between the Kelvin-Helmholtz instability mechanism and the entrainment in paraffin-based hybrid rocket engines, by means of optical investigations on combustion tests. Although the stability of liquid layers has been extensively studied in the past (Craik 1966; Chang and Russel 1965; Nayfeh and Saric 1971), even under strong blowing conditions (Gater and L'Ecuyer 1970; Nigmatulin et al. 1996; Ishii and Grolmes 1975), the behaviour of films under real combustion conditions has not been explored yet. The presented work confirms the results of the linear stability theory for a liquid film postulated by Karabeyoglu et al. (2002) and Karabeyoglu and Cantwell (2002), which led to a general empirical expression for the entrainment rate of liquid droplets in terms of the relevant properties of the hybrid motor (i.e., mass flux, liquid layer thickness, surface tension and liquid viscosity, see Fig. 1). In addition to that, in the framework of this research, a direct dependency of the droplets entrainment rate (i.e., regression rate) on the liquid layer instability mechanism has been found, for every analysed liquid fuel viscosity and oxidizer mass flow. This means that it is possible to directly control the fuel regression rate by triggering precise frequencies and wavelengths of the liquid layer. The next step will be the investigation of the chamber pressure influence on the liquid layer stability and, consequently, on the entrainment process.

Acknowledgements This work was partially funded by the DLR project ATEK (Antriebstechnologien und Komponenten fuer Traegersysteme: Propulsion Technologies and Components for Launcher Systems). The support of the M11 team and the propellants department is greatly acknowledged.

Open Access This article is distributed under the terms of the Creative Commons Attribution 4.0 International License (http://creativeco mmons.org/licenses/by/4.0/), which permits unrestricted use, distribution, and reproduction in any medium, provided you give appropriate credit to the original author(s) and the source, provide a link to the Creative Commons license, and indicate if changes were made.

\section{References}

Amano RS, Yen Y-H, Miller TC, Ebnit A, Lightfoot M, Sankaran V (2016) Study of the liquid breakup process in solid rocket motor. J Spacecr Rockets 53(5):980-992

Bizon K, Continillo G, Lombardi S, Mancaruso E, Vaglieco B (2013a) Spatial and temporal independent component analysis of flame dynamics in diesel engine. In XXXVI Meeting of the Italian Section of the Combustion Institute

Bizon K, Lombardi S, Continillo G, Mancaruso E, Vaglieco BM (2013b) Analysis of diesel engine combustion using imaging and independent component analysis. Proc Combust Inst 34(2):2921-2931

Chandler AA (2012) An investigation of liquefying hybrid rocket fuels with applications to solar system exploration. Ph.D. thesis, Stanford University

Chandler AA, Jens ET, Cantwell BJ, Hubbard GS (2012a) Visualization of the liquid layer combustion of paraffin fuel at elevated pressures. In: 63rd International Astronautical Congress

Chandler AA, Jens ET, Cantwell BJ, Hubbard GS (2012b) Visualization of the liquid layer combustion of paraffin fuel for hybrid rocket applications. In: 48th AIAA/ASME/SAE/ASEE joint propulsion conference and exhibit. American Institute of Aeronautics and Astronautics

Chang I-D, Russel PE (1965) Stability of a liquid layer adjacent to a high-speed gas stream. Phys Fluids 8(6):1018-1026

Chatterjee A (2000) An introduction to the proper orthogonal decomposition. Curr Sci 78(7):808-817

Chiaverini M (2007) Review of solid-fuel regression rate behavior in classical and nonclassical hybrid rocket motors. In: Fundamentals of hybrid rocket combustion and propulsion. American Institute of Aeronautics and Astronautics, pp 37-126

Ciezki HK, Sender J, Clau-oslash W, Feinauer A, Thumann A (2003) Combustion of solid-fuel slabs containing boron particles in step combustor. J Propuls Power 19(6):1180-1191

Craik ADD (1966) Wind generated waves in thin liquid films. J Fluid Mech 26(Pt 2):369-392

DeLuca LT, Galfetti L, Maggi F, Colombo G, Paravan C, Reina A, Tadini P, Sossi A, Duranti E (2011) An optical time-resolved technique of solid fuels burning for hybrid rocket propulsion. In: 47th 
AIAA/ASME/SAE/ASEE joint propulsion conference and exhibit. American Institute of Aeronautics and Astronautics

Funada T, Joseph DD (2001) Viscous potential flow analysis of KelvinHelmholtz instability in a channel. J Fluid Mech 445:263-283

Gater RA, L'Ecuyer MR (1970) A fundamental investigation of the phenomena that characterize liquid film cooling. Int J Heat Mass Transf 13(3): 1925-1939

Geladi P, Kowalski BR (1986) Partial least-squares regression: a tutorial. Anal Chim Acta 185:1-17

Hyvarinen A (1997) One-unit contrast functions for independent component analysis: a statistical analysis. In: Neural networks for signal processing VII. Proceedings of the 1997 IEEE Workshop

Hyvarinen A, Oja E (2000) Independent component analysis: algorithms and applications. Neural Netw 13(4-5):411-430

Ishii M, Grolmes MA (1975) Inception criteria for droplet entrainment in two-phase concurrent film flow. AIChE J 21(2):308-318

Jens ET, Chandler AA, Cantwell B, Hubbard GS, Mechentel F (2014a) Combustion visualization of paraffin-based hybrid rocket fuel at elevated pressures. In: 50th AIAA/ASME/SAE/ASEE joint propulsion conference. American Institute of Aeronautics and Astronautics

Jens ET, Narsai P, Cantwell B, Hubbard GS (2014b) Schlieren imaging of the combustion of classical and high regression rate hybrid rocket fuels. In: 50th AIAA/ASME/SAE/ASEE joint propulsion conference. American Institute of Aeronautics and Astronautics

Jens ET, Miller VA, Mechentel FS, Cantwell BJ, Hubbard S (2015) A visual study of the combustion of high-regression rate and classical hybrid rocket fuels. In: 51st AIAA/SAE/ASEE joint propulsion conference. American Institute of Aeronautics and Astronautics

Jens ET, Miller VA, Cantwell BJ (2016) Schlieren and oh* chemiluminescence imaging of combustion in a turbulent boundary layer over a solid fuel. Exp Fluids 57(39):1-16

Karabeyoglu A, Altman D, Cantwell BJ (2002) Combustion of liquefying hybrid propellants: part 1, general theory. J Propuls Power 18(3):610-620

Karabeyoglu A, Cantwell B, Altman D (2001) Development and testing of paraffin-based hybrid rocket fuels. In: 37th AIAA/ASME/SAE/ ASEE joint propulsion conference and exhibit. American Institute of Aeronautics and Astronautics, Salt Lake City

Karabeyoglu A, Cantwell BJ (2002) Combustion of liquefying hybrid propellants: part 2, stability of liquid films. J Propuls Power 18(3):621-630

Karabeyoglu A, Zilliac G, Cantwell BJ, DeZilwa S, Castellucci P (2004) Scale-up tests of high regression rate paraffin-based hybrid rocket fuels. J Propuls Power 20(6):1037-1045

Karabeyoglu A, Cantwell BJ, Stevens J (2005) Evaluation of homologous series of normal-alkanes as hybrid rocket fuels. In: 41st AIAA/ASME/ASEE joint propulsion conference

Kerschen G, Claude Golinval J, Vakakis AF, Bergman LA (2005) The method of proper orthogonal decomposition for dynamical characterization and order reduction of mechanical systems: an overview. Nonlinear Dyn 41(1-3):147-169

Kobald M, Ciezki HK, Schlechtriem S (2013) Optical investigation of the combustion process in paraffin-based hybrid rocket fuels. In: 49th AIAA/ASME/SAE/ASEE joint propulsion conference. American Institute of Aeronautics and Astronautics

Kobald M, Fischer U, Tomilin K, Petrarolo A, Kysela P, Schmierer C, Pahler A, Gauger J, Breitinger J, Hertel F (2017a) Sounding rocket "heros"- a low-cost hybrid rocket technology demonstrator. In: 53rd AIAA/SAE/ASEE joint propulsion conference, Atlanta, GA

Kobald M, Fischer U, Tomilin K, Petrarolo A, Schmierer C (2017b) Hybrid experimental rocket stuttgart: a low-cost technology demonstrator. J Spacecr Rockets. https://doi.org/10.2514/1.A34035. Accessed 28 Nov 2017

Kobald M, Schlechtriem S (2013) Investigation of different hybrid rocket fuels in a $2 \mathrm{~d}$ slab burner with optical techniques. In: Tenth international conference on flow dynamics
Kobald M, Schmierer C, Ciezki HK, Schlechtriem S, Toson E, DeLuca LT (2017c) Viscosity and regression rate of liquefying hybrid rocket fuels. J Propuls Power 33(5):1245-1251

Kobald M, Toson E, Ciezki H, Schlechtriem S, di Betta S, Coppola M, DeLuca LT (2016) Rheological, optical, and ballistic investigations of paraffin-based fuels for hybrid rocket propulsion using a two-dimensional slab-burner. EUCASS Proc Ser Adv AeroSp Sci 8:263-282

Kobald M, Verri I, Schlechtriem S (2015) Theoretical and experimental analysis of liquid layer instability in hybrid rocket engines. CEAS Space J 7(1):11-22

Kuo K, Houim R (2011) Theoretical modeling and numerical simulation challenges of combustion processes of hybrid rockets. In: 47th AIAA/ASME/SAE/ASEE joint propulsion conference and exhibit. American Institute of Aeronautics and Astronautics

Marano JJ, Holder GD (1997a) A general equation for correlating the thermophysical properties of n-paraffins, n-olefins, and other homologous series. 3. Asymptotic behavior correlations for thermal and transport properties. Ind Eng Chem Res 36(6):2399-2408

Marano JJ, Holder GD (1997b) General equation for correlating the thermophysical properties ofn-paraffins, n-olefins, and other homologous series. 1. Formalism for developing asymptotic behavior correlations. Ind Eng Chem Res 36(5):1887-1894

Marano JJ, Holder GD (1997c) General equation for correlating the thermophysical properties ofn-paraffins, n-olefins, and other homologous series. 2. Asymptotic behavior correlations for pvt properties. Ind Eng Chem Res 36(5):1895-1907

Marxman G, Gilbert M (1963) Turbulent boundary layer combustion in the hybrid rocket. In: 9th symposium (international) on combustion. Elsevier, pp 371-383

Marxman G, Muzzy R, Wooldridge C (1963) Fundamentals of hybrid boundary layer combustion. In: Heterogeneous combustion conference. American Institute of Aeronautics and Astronautics

Nakagawa I, Hikone S (2011) Study on the regression rate of paraffinbased hybrid rocket fuels. J Propuls Power 27(6):1276-1279

Nayfeh AH, Saric WS (1971) Non-linear kelvin-helmholtz instability. J Fluid Mech 46(Pt 2):209-231

Nigmatulin RI, Nigmatulin BI, Khodzhaev YD, Kroshilin VE (1996) Entrainment and deposition rates in a dispersed-film flow. Int $\mathbf{J}$ Multiph Flow 22(1):19-30

Pelletier N (2009) Etude des Phenomenes de Combustion dans un Propulseur Hybride. Modelisation et Analyse Experimentale de la Regression des Combustibles Liquefiables. Ph.D. thesis, Institut Superieur de L'Aeronatique et de L'Espace, Toulouse

Petrarolo A, Kobald M (2016) Evaluation techniques for optical analysis of hybrid rocket propulsion. J Fluid Sci Technol 11(4):JFST0028

Petrarolo A, Kobald M, Schlechtriem S (2017) Optical analysis of the liquid layer combustion of paraffin-based hybrid rocket fuels. In: 7th European conference for aeronautics and aerospace sciences (EUCASS)

Risvik H (2007) Principal component analysis (PCA) \& NIPALS algorithm

Stone JV (2004) Independent component analysis: a tutorial introduction. MIT Press, Boston

Thumann A, Ciezki HK (2002) Combustion of energetic materials chap. In: Comparison of PIV and Colour-Schlieren measurements of the combusiton process of boron particle containing soild fuel slabs in a rearward facing step combustor, vol 5. Begell House Inc, Danbury, pp 742-752

Wada Y, Kawabata Y, Itagaki T, Seki K, Kato R, Kato N, Hori K (2014) Observation of combustion behavior of low melting temperature fuel for hybrid rocket using double slab motor. In: 10th international symposium on special topics in chemical propulsion 